\title{
System-level evaluation of dicyandiamide (DCD) for improved environmental outcomes on New Zealand dairy farms
}

\author{
G.J. DOOLE ${ }^{1,2}$ and U.H. PARAGAHAWEWA ${ }^{3}$ \\ ${ }^{1}$ University of Western Australia, 35 Stirling Highway, Crawley, WA 6009, Australia \\ ${ }^{2}$ University of Waikato, Private Bag 3105, Hamilton \\ ${ }^{3}$ AgResearch, Ruakura Research Centre, Private Bag 3123, Hamilton \\ gdoole@uwa.edu.au
}

\begin{abstract}
Nitrification inhibitors are an important mitigation practice for nitrate leaching since they reduce leaching loads and can potentially increase farm profit through promoting pasture production. This study investigated the role and value of a nitrification inhibitor on a representative dairy farm in the Waikato region using a whole-farm bioeconomic model. Given an assumed $10 \%$ pasture growth response, nitrogen inhibitors like dicyandiamide (DCD) are a critical component of the optimal set of mitigation practices required to satisfy regulatory goals. Model output highlights that the net benefits associated with nitrification inhibitors are positive, but are likely too low to warrant their widescale adoption for improved environmental outcomes without direct regulation. Thus, reliance on voluntary approaches to acquire high mitigation levels on New Zealand dairy farms continues to be inherently constrained by a lack of profitable practices.
\end{abstract}

Keywords: nitrate leaching, bioeconomic model, environmental policy

\section{Introduction}

The detrimental implications of agricultural intensification for water quality have stimulated the development and extension of multiple strategies for reducing nitrate leaching on New Zealand dairy farms (Monaghan 2009). One such innovation is dicyandiamide (DCD) that inhibits the conversion of ammonium to nitrate during the process of nitrification, increasing the probability that nitrogen $(\mathrm{N})$ is retained in the soil and thereby decreasing leaching and increasing pasture production (Moir et al. 2007). AgFirst Waikato (2009) identified that its use was profitable where cows could not be grazed off-farm. However, no study has yet provided an analysis of the role and value of this innovation at the system level. This is an important deficiency since the development of technologies that promote environmental outcomes while increasing producer profit is essential to achieve wide-scale improvements in water quality without imposing large costs on society. This is particularly important if mitigation is going to be achieved through voluntary action and not direct regulation, as the voluntary adoption of conservation practices is directly related to the degree to which a technology is perceived to benefit a producer over and above standard management (Pannell et al. 2006). The primary objective of this paper is therefore to assess the role and value of a nitrification inhibitor for a representative New Zealand dairy farm.

\section{Methods \\ Model}

IDEAL (Integrated Dairy Enterprise Analysis modeL) is a non-linear programming (NLP) model based on McCall et al. (1999) and Doole (2010). IDEAL consists of 26 fortnightly feeding periods in each year to provide detailed insight into temporal feed allocation. In each period farm area is grazed, harvested for grass silage or rested for future use. The model determines the optimal proportion of the farm on which DCD is used. Grass growth on these areas is promoted given the positive impact of DCD on pasture production (e.g. Moir et al. 2007).

Cows consume grazed pasture and supplementary feeds (grass silage harvested on-farm, concentrates and maize silage). Grazing or silage production can only occur between pasture biomass thresholds that ensure the maintenance of seasonal feed quality and maximise opportunities for regrowth. Moreover, silage can only be produced at certain times of the year when pasture supply is excess to livestock requirements. Nitrogen fertiliser application increases pasture biomass in subsequent periods.

Metabolisable energy (ME) for allocation among livestock classes in a given time period is derived from all available feed sources. This is used to sustain the most profitable combination of individual cows, each possessing one of 216 alternative sets of attributes, involving different temporal energy demands due to varying calving date, herd status (cull versus standard), lactation length, and productivity. See Doole (2010) for more information on attribute calculation.

Nitrate loads can be decreased by reducing $\mathrm{N}$ fertiliser application, stocking rate or per cow milk production or by using low $\mathrm{N}$ feed, low-rate effluent application, a 
Dungbuster ${ }^{\circledR}$ system (this helps to reduce wash down water volume through automation), deferred effluent application, a feed pad and nitrification inhibitors.

The objective function defines the maximisation of farm profit. Total revenue is earned from the sale of milk, culled cows and excess calves. Total cost is the sum of general variable costs incurred for each cow, fixed costs incurred per hectare of farm area, cost of silage production, cost of maize silage, cost of concentrates, cost of nitrogen fertiliser and cost of mitigation strategies such as use of nitrification inhibitors.

\section{Parameter estimation}

Parameter values for the model were taken from scientific publications, expert opinion and survey data. The model was calibrated to represent a standard farm with allophanic soils in the Waikato region in the 2008/09 milking season. Average farm size was assumed to be 109 ha (MAF 2009). Energy demand for each cow attribute was computed using a simulation model constructed based on information from DairyNZ (2008b).

Average pasture production was taken from DairyNZ (2008a). Increases in pasture production associated with the use of nitrification inhibitors were provided by J. Moir (Lincoln University). It is assumed that nitrification inhibitors increase pasture growth by 10 per cent overall, with two-thirds of this increase experienced over July-December and one-third from January-June. The production benefits associated with nitrification inhibitors are the subject of ongoing debate. Nevertheless, it is outlined below that this assumption has little impact on the key findings of this study.

Nitrogen leaching amounts were calculated for numerous combinations of maize silage use, milk production, $\mathrm{N}$ fertiliser use, and stocking rate using the OVERSEER model. A meta-model was generated through regression of these data. The efficacy of alternative mitigations was from the BMP Toolbox (Monaghan 2009).

The milk price for 2008/09 (\$5 140/t MS) was taken from LIC (2009). The cost of mitigation strategies was taken from AgFirst Waikato (2009), Longhurst \& Smeaton (2008) and Monaghan (2009). The standard cost of nitrification inhibitors was $\$ 160 /$ ha (Longhurst \& Smeaton 2008).

The farm model incorporates 13605 equations and 8 656 decision variables. It was solved using NLP in the CONOPT3 solver in GAMS v23 (Brooke et al. 2008).

\section{Results and Discussion \\ Output of base model}

Standard output of the model provided a meaningful description of a representative Waikato dairy farm (Table 1; "without inhibitors" column). The farm had a stocking rate of 3.03 cows/ha, each with an average output of $311 \mathrm{~kg} \mathrm{MS} / \mathrm{cow}$; both of these variables are within $1 \%$ of a typical farm in this region (LIC 2009). The leaching load was around $37 \mathrm{~kg} \mathrm{~N} / \mathrm{ha} / \mathrm{yr}$, a typical load for a farm with this level of production. The total amount of feed consumed was $17.76 \mathrm{t} \mathrm{DM} /$ ha, incorporating $16.18 \mathrm{t} \mathrm{DM} /$ ha of grazed pasture, 1.44 $\mathrm{t} \mathrm{DM} / \mathrm{ha}$ of grass silage and $0.139 \mathrm{t} \mathrm{DM} / \mathrm{ha}$ of maize silage. Cows are milked for 270 days and consumed 54 $749 \mathrm{MJ} / \mathrm{cow} / \mathrm{yr}$, on average. These values are broadly representative of a typical farm within the region; thus, this model is an appropriate framework in which to evaluate the impact of nitrification inhibitors.

\section{Value of a nitrification inhibitor under standard assumptions}

DCD is applied to around $89 \%$ of the farm at the standard parameter values (Table 1). Stocking rate

Table 1 Impact on nitrification inhibitors on key model output at the standard milk price (\$5 $140 \mathrm{t} / \mathrm{MS}$ ).

\begin{tabular}{lccc}
\hline Variable & Without inhibitors & With inhibitors & Difference (\%) \\
\hline N inhibitor application (ha) & - & 97 & - \\
Farm profit (\$/ha) & 1705 & 1744 & +2.3 \\
Stocking rate (cows/ha) & 3.03 & 3.19 & +5.3 \\
Milk production (kg MS/cow) & 311 & 311 & 0 \\
Milk production (kg MS/ha) & 942 & 992 & +5.3 \\
N fertiliser application (kg/ha) & 166 & 165 & -0.6 \\
N leaching (kg N/ha) & 37.13 & 33.86 & -8.8 \\
Total feed (t DM/ha) & 17.76 & 18.66 & +5.1 \\
Total grazed pasture (t DM/ha) & 16.18 & 16.89 & +4.4 \\
Total grass silage (t DM/ha) & 1.44 & 1.63 & +13.2 \\
Total maize silage (t DM/ha) & 0.139 & 0.156 & +12.2 \\
Total energy per cow (MJ/cow) & 54,749 & 54,518 & -0.4 \\
Lactation length (days) & 270 & 270 & 0 \\
\hline
\end{tabular}


increased by $5.3 \%$ due to greater pasture production; however, profit only increased by $2.3 \%$. Higher levels of pasture growth increased the intake of grazed pasture $(4.4 \%)$ and grass silage $(13.2 \%)$. In addition, the higher stocking rate motivated an increase in the use of supplement (12.2\%). Nitrate leaching decreased by around $9 \%$, indicating that the mitigation effect of the inhibitor outweighed the impact of increases in stocking rate on nitrate emissions.

\section{Impact of a nitrification inhibitor on leaching loads}

A key motivation for the use of nitrification inhibitors is their value for reducing nitrate leaching. It is claimed that a $30 \%$ reduction in nitrate leaching is required in the catchment of the Waikato River for water to be suitable for irrigation, while a $50 \%$ reduction is required to satisfy contact recreation benchmarks (Vant
2006). A $30 \%$ reduction is required in the model to achieve leaching of $26 \mathrm{~kg} \mathrm{~N} / \mathrm{ha}$, a threshold at which it is proposed no further degradation in the Waikato River will occur (AgFirst Waikato 2009).

Costs incurred to achieve the 30 and $50 \%$ mitigation goal are substantial in the absence of nitrification inhibitors, as these costs are 20 and $37 \%$ of income, respectively. In contrast, the use of nitrification inhibitors reduces abatement costs markedly, with reductions in income of 8 and $28 \%$ to achieve the 30 and $50 \%$ goals, respectively.

Nitrification inhibitors are valuable because they offset costly reductions in stocking rates and $\mathrm{N}$ fertiliser application. For example, stocking rate and $\mathrm{N}$ fertiliser application decreased by 0.6 (6) and 17 (35)\%, respectively, to achieve the $30 \%$ leaching reduction when nitrification inhibitors are available

Table 2 Changes in leaching load associated with each mitigation strategy ( $\mathrm{kg} \mathrm{N} / \mathrm{ha} / \mathrm{yr}$ ), relative to standard management, for regulated decreases in farm emissions. For example, the higher stocking rate observed under a 10 per cent regulation increases leaching by $1.97 \mathrm{~kg} \mathrm{~N} / \mathrm{ha} / \mathrm{yr}$, but this is offset by inhibitor use that reduces leaching by $5.19 \mathrm{~kg} \mathrm{~N} / \mathrm{ha} / \mathrm{yr}$.

\begin{tabular}{lllll}
\hline Mitigation & \multicolumn{4}{l}{ Regulated decrease in nitrate leaching (\%) } \\
& 10 & 30 & 50 & 70 \\
\hline Stocking rate & +1.97 & +1.73 & -2.36 & -9.94 \\
N fertiliser & -0.13 & -1.28 & -2.42 & -3.56 \\
Milk production & -0.027 & -0.13 & -0.03 & +0.14 \\
Maize silage & -0.37 & -0.1 & +0.02 & +0.17 \\
Low rate effluent application & 0 & 0 & 0 & -0.06 \\
Dungbuster system & -0.31 & -2.24 & -1.94 & -1.44 \\
Defer effluent application ${ }^{1}$ & 0 & -3.55 & -3.08 & -2.27 \\
Nitrification inhibitors & -5.19 & -5.60 & -4.86 & -3.59 \\
Feed pad & 0 & 0 & -3.94 & -5.39 \\
Net reduction & -3.724 & -11.17 & -18.61 & -25.94 \\
\hline
\end{tabular}

${ }^{1}$ This mitigation requires the storage of effluent and its tactical application in response to observed soil-water balance.

Table 3 Important model output when DCD price and pasture production response is varied. Highlighted row presents output from the base model.

\begin{tabular}{|c|c|c|c|c|c|}
\hline \multicolumn{2}{|c|}{ Parameter values } & \multicolumn{4}{|c|}{ Key model output } \\
\hline $\begin{array}{l}\text { Cost of inhibitor } \\
\qquad \$ / h a)\end{array}$ & $\begin{array}{l}\text { Increase in } \\
\text { pasture (\%) }\end{array}$ & Farm profit (\$/ha) & $\begin{array}{l}\text { Stocking rate } \\
\text { (cows/ha) }\end{array}$ & Inhibitor use (ha) & $\begin{array}{c}\mathrm{N} \text { leaching (kg } \\
\mathrm{N} / \mathrm{ha})\end{array}$ \\
\hline 100 & 0 & 1705 & 3.03 & 0 & 37 \\
\hline 100 & 5 & 1711 & 3.11 & 97 & 33 \\
\hline 100 & 10 & 1801 & 3.20 & 109 & 33 \\
\hline 100 & 15 & 1904 & 3.29 & 109 & 34 \\
\hline 160 & 0 & 1705 & 3.03 & 0 & 37 \\
\hline 160 & 5 & 1705 & 3.03 & 0 & 37 \\
\hline 160 & 10 & 1744 & 3.19 & 97 & 34 \\
\hline 160 & 15 & 1844 & 3.29 & 109 & 34 \\
\hline 220 & 0 & 1705 & 3.03 & 0 & 37 \\
\hline 220 & 5 & 1705 & 3.03 & 0 & 37 \\
\hline 220 & 10 & 1705 & 3.05 & 0 & 37 \\
\hline 220 & 15 & 1784 & 3.29 & 109 & 34 \\
\hline
\end{tabular}


(unavailable). Nonetheless, this benefit of nitrification inhibitors is inherently exhaustible. DCD use reduced total nitrate leaching by $86,35,26$, and $14 \%$ of that required for regulated decreases of $10,30,50$, and $70 \%$ in leaching load, respectively (Table 2). Thus, DCD alone is not sufficient to reduce the environmental impact of dairy farming to the level required for widescale improvements in water quality.

\section{Sensitivity analysis}

Nitrification inhibitors had a slight economic benefit in the model with an assumed 10 per cent pasture growth response. However, inhibitors were not adopted at their standard cost if pasture production gains fell to 5 per cent or below (Table 3). This is important as the production benefits associated with the use of DCD are subject to much conjecture.

\section{Conclusions}

Given an assumed $10 \%$ pasture growth response, DCD was a profitable technology in the modelling scenarios considered. However, its profitability is low compared with standard management, increasing returns by around $2 \%$. Moreover, sensitivity analysis highlights that it will not be adopted if its impact on pasture production decreases below 5\%. Overall, this study demonstrates that DCD will play an important role in decreasing mitigation costs on farms regulated to achieve public environmental outcomes. However, reliance on voluntary approaches to acquire high levels of abatement on New Zealand dairy farms continues to be inherently constrained by a lack of profitable mitigation practices.

\section{ACKNOWLEDGEMENTS}

The authors wish to acknowledge the help of Jim Moir (Lincoln University) and David Pannell (University of Western Australia). Funding for this study was provided by the Foundation of Research, Science, and Technology.

\section{REFERENCES}

AgFirst Waikato. 2009. Upper Waikato nutrient efficiency study. AgFirst Waikato, Hamilton.
Brooke, A.; Kendrick, D.; Meeraus, A.; Raman, R. 2008. GAMS-A user's guide. GAMS Development Corporation, Washington D.C.

DairyNZ. 2008a. Average pasture growth data for New Zealand dairy farms. DairyNZ, Hamilton.

DairyNZ. 2008b. Feed information sheet. DairyNZ, Hamilton.

Doole, G.J. 2010. Indirect instruments for nonpoint pollution control with multiple, dissimilar agents. Journal of Agricultural Economics (In Press).

Livestock Improvement Corporation (LIC). 2009. 2008/09 dairy statistics. Livestock Improvement Corporation, Hamilton.

Longhurst, R.D.; Smeaton, D.C. 2008. Improved nutrient efficiency through integrated catchment management in Little Waipa and Waipapa. AgResearch, Hamilton. McCall, D.G.; Clark, D.A.; Stachurski, L.J.; Penno, J.W.; Bryant, A.M.; Ridler, B.J. 1999. Optimised dairy grazing systems in the Northeast United States and New Zealand. 1. Model description and evaluation. Journal of Dairy Science 82: 1795-1807.

Ministry of Agriculture and Forestry (MAF). 2009. Pastoral sector overview. Ministry of Agriculture and Forestry, Wellington.

Moir, J.; Cameron, K.C.; Di, H.J. 2007. Effects of the nitrification inhibitor dicyandiamide on soil mineral $\mathrm{N}$, pasture yield, nutrient uptake, and pasture quality in a grazed pasture system. Soil Use and Management 23: 111-120.

Monaghan, R.M. 2009. The BMP Toolbox-selecting the right best management practice for mitigating farming impacts on water quality. pp. 328-334. In: Nutrient management in a rapidly changing world. Eds. Currie, L.D.; Yates, L.J. Massey University Fertiliser and Lime Research Centre Occasional Report No. 22, Palmerston North.

Pannell, D.J.; Marshall, G.R.; Barr, N.; Curtis, A.; Vanclay, F.; Wilkinson, R. 2006. Understanding and promoting adoption of conservation practices by rural landholders. Australian Journal of Experimental Agriculture 46: 1407-1424.

Vant, W. 2006. Water quality effects of land use changes in the catchment of the Waikato River hydrolakes. Environment Waikato, Hamilton. 